\title{
Caulobacter species as a cause of postneurosurgical bacterial meningitis in a pediatric patient
}

\author{
Natalie Bridger $M D^{1}$, Andrew Walkty $M D^{2,3}$, Maryanne Crockett $\mathrm{MD}^{1,4}$, \\ Sergio Fanella $\mathrm{MD}^{1}$, Kim Nichol $\mathrm{MSc}^{3}$, James A Karlowsky $\mathrm{PhD}^{3,4}$
}

\begin{abstract}
N Bridger, A Walkty, M Crockett, S Fanella, K Nichol, JA Karlowsky. Caulobacter species as a cause of postneurosurgical bacterial meningitis in a pediatric patient. Can J Infect Dis Med Microbiol 2012;23(1):e10-e12.

Caulobacter species have been rarely found to be a cause of human infection. A case of probable Caulobacter species meningitis occurring postneurosurgery in a pediatric patient is reported in the present article. Gram stain and colony morphology of the isolate were not consistent with the identification provided by commercial phenotypic identification systems. The present case illustrates the need to reconcile conflicting phenotypic test results using $16 \mathrm{~S}$ ribosomal DNA sequencing.
\end{abstract}

Key Words: Caulobacter; Meningitis; Sequencing

\author{
Des espèces de Caulobacter responsables d'une \\ méningite bactérienne postneurochirurgicale chez \\ un patient d'âge pédiatrique
}

\begin{abstract}
Les espèces de Caulobacter sont rarement responsables d'infections chez les humains. Les auteurs rendent compte d'un cas probable de méningite à espèces de Caulobacter après une neurochirurgie chez un patient d'âge pédiatrique. La coloration de Gram et la morphologie des colonies de l'isolat ne correspondaient pas aux résultats obtenus par les systèmes de repérage phénotypiques commerciaux. Le présent cas démontre la nécessité de réconcilier les résultats des tests phénotypiques conflictuels au moyen du séquençage d'ADN ribosomique $16 \mathrm{~S}$.
\end{abstract}

Caulobacter species are aerobic, Gram-negative bacilli that have a aulobacter species are aerobic, Gram-negative bacilli that have a
rod-shaped, fusiform or vibrioid appearance, and are characterized by the presence of a stalk (1-3). These bacteria have been primarily recovered from aquatic environments (1). There are very few published reports in the literature describing isolation of Caulobacter species from human clinical specimens. A probable case of Caulobacter species meningitis occurring postneurosurgery is presented in the current report, as well as a description of the genus and review of the literature.

\section{CASE PRESENTATION}

A 14-year-old boy with a history of Chiari I malformation and multiple previous neurosurgical procedures was admitted to a tertiary care hospital (Winnipeg, Manitoba) in May 2009 with a diagnosis of bacterial meningitis. The patient had undergone Chiari decompression surgery three weeks prior to admission. Two weeks before admission, he developed a postoperative cerebrospinal fluid (CSF) leak, which required resuturing of the surgical incision. On admission, the patient reported three days of swelling below the incision, back and neck pain, and low-grade fever (measured temperature of $38.3^{\circ} \mathrm{C}$ ). On physical examination, the patient was noted to have a pseudomeningocele swelling of the nape of the neck. He was afebrile $\left(36.8^{\circ} \mathrm{C}\right)$ at this time. The patient's peripheral white blood cell count demonstrated a neutrophilic leukocytosis $\left(15.5 \times 10^{9} / \mathrm{L}\right)$. Due to the clinical concern of meningitis, CSF sampling was performed. Eighty millilitres of turbid CSF was drained from the pseudomeningocele. CSF analysis demonstrated a total nucleated cell count of $2174 \times 10^{6} / \mathrm{L}$ ( $73 \%$ neutrophils), a protein concentration of $1.05 \mathrm{~g} / \mathrm{L}$, and a glucose level of $2.1 \mathrm{mmol} / \mathrm{L}$. Bacteria were not visualized on Gram stain. Empirical antimicrobial therapy with vancomycin and ceftazidime was initiated after the CSF specimen was obtained.

The CSF was centrifuged $(10,000 \mathrm{~g}$ for $15 \mathrm{~min})$, the supernatant was decanted, and the resuspended pellet was inoculated into a pediatric blood culture bottle and streaked onto 5\% sheep blood agar and chocolate agar plates. The blood culture bottle was incubated in a
BacTALERT 3D (BioMérieux, USA) automated instrument. Growth was only observed in the pediatric bottle (not on the plates), following three days of incubation. Gram staining revealed a Gram-negative, curved rod (Figure 1). The isolate was subcultured onto 5\% sheep blood agar, Mueller-Hinton agar, chocolate agar and MacConkey agar, and was incubated at $35^{\circ} \mathrm{C}$ in an aerobic atmosphere $\left(5 \% \mathrm{CO}_{2}\right.$ for the chocolate agar). Slight growth was visible on all plates after $24 \mathrm{~h}$ incubation. The colonies on blood agar after three days of incubation were small (approximately $1 \mathrm{~mm}$ ), gray and circular, with a slight central depression (Figure 1). The isolate was oxidase positive and indole negative. A catalase test was indeterminate.

Biochemical identification with the API 20 NE (BioMérieux) and VITEK 2 GN (BioMérieux) systems was performed. These systems identified the isolate as Brevundimonas vesicularis (probability 93.7\%) and Sphingomonas paucimobilis (probability 95\%), respectively. However, the phenotype of the isolate (curved rods with gray colonies) was inconsistent with that of either B vesicularis or S paucimobilis. These bacteria are typically described as straight rods with yellow colonies.

To definitively identify the isolate, polymerase chain reaction amplification and sequencing of an 800 base pair fragment of the 16S ribosomal RNA gene was performed, using universal primers 8FPL (5'-AGTTTGATCCTGGCTCAG-3') and 806R (5'-GGACTACCAGGGTATCTAAT-3'). The sequence obtained was compared with sequences deposited in the GenBank (NCBI, USA) and Ribosomal Database Project (Michigan State University, USA) databases. The isolate was identified as Caulobacter species (100\% sequence identity with Caulobacter species DNA, GenBank accession numbers AJ227773.1, AJ227764.1, AJ227761.1).

Antimicrobial susceptibility of the isolate was determined by broth microdilution in accordance with the Clinical and Laboratory Standards Institute (CLSI) guidelines (4). Because there are no published breakpoints for Caulobacter species, the CLSI minimum inhibitory concentration interpretive standards for non-Enterobacteriaceae Gram-negative rods were applied (5). The isolate's

${ }^{1}$ Department of Pediatrics and Child Health, University of Manitoba; ${ }^{2}$ Department of Medicine; ${ }^{3}$ Department of Clinical Microbiology,

Health Sciences Centre; ${ }^{4}$ Department of Medical Microbiology, Faculty of Medicine, University of Manitoba, Winnipeg, Manitoba

Correspondence: Dr Andrew Walkty, Departments of Medicine and Clinical Microbiology, Health Sciences Centre, MS673B-820 Sherbrook

Street, Winnipeg, Manitoba R3A 1R9. Telephone 204-453-3867, fax 204-787-4699, e-mail Awalkty@mts.net 


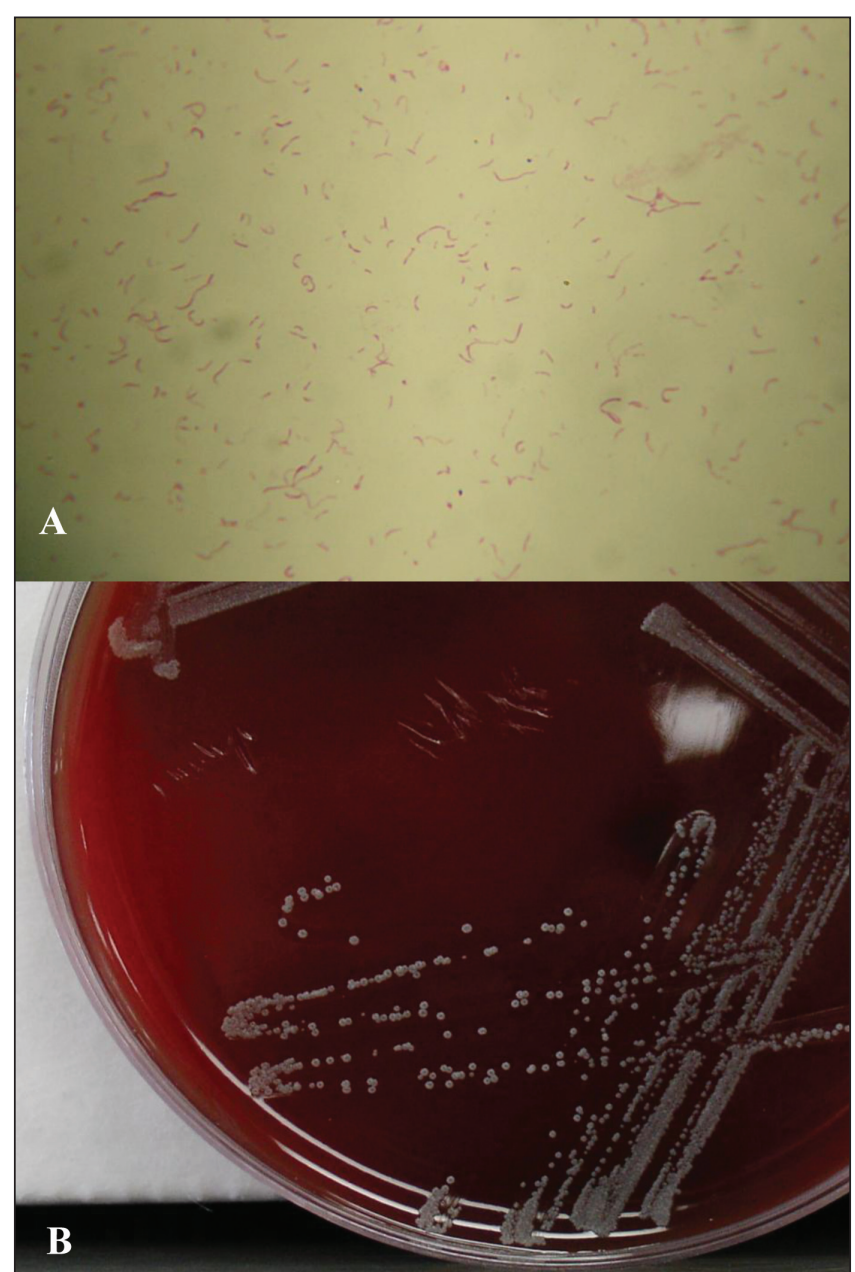

Figure 1) Caulobacter species isolate obtained from cerebrospinal fluid. A Curved Gram-negative bacilli seen on Gram stain; B Colony morphology after three days of incubation on blood agar

susceptibility profile is presented in Table 1 . The patient was switched to vancomycin and meropenem on day 7 of his admission. He completed a 14-day course of intravenous antibiotics, and made an uneventful recovery.

\section{DISCUSSION}

In 1935, Henrici and Johnson (2) published the first description of microorganisms belonging to the genus Caulobacter. The genus name was derived from the Greek word 'Kaulos' meaning 'stalk' (2). Caulobacter species are aerobic, Gram-negative, unicellular, stalked bacteria that measure $0.4 \mu \mathrm{m}$ to $0.5 \mu \mathrm{m} \times 1 \mu \mathrm{m}$ to $2 \mu \mathrm{m}$ (3). The cells may be vibrioid, rod shaped or fusiform, with the stalk arising from one pole of the cell (1-3). Members of the genus form catalase (1). The temperature for optimal growth is $25^{\circ} \mathrm{C}$ to $30^{\circ} \mathrm{C}$ (range $10^{\circ} \mathrm{C}$ to $35^{\circ} \mathrm{C}$ ), and some species have specific nutritional requirements (eg, riboflavin, biotin) $(1,6,7)$.

Caulobacter species have been recovered primarily from freshwater (river, canal, well, pond, tap, distilled and bottled water) and marine (seawater) sources. Isolates have also been obtained from soil, and the intestinal tract of millipedes $(1,6,8,9)$. Phylogenetically, the freshwater Caulobacter species form two distinct clusters (10). Marine species form an additional cluster, which is more distantly related to the freshwater species. Through $16 \mathrm{~S}$ ribosomal DNA sequencing, the freshwater species, including Caulobacter crescentus (similar to the isolate in the present report with regard to sequencing), are most closely related

\section{TABLE 1}

Antibiotic susceptibility of Caulobacter species isolate

\begin{tabular}{lcc}
\hline Antibiotic & MIC, $\boldsymbol{\mu g} / \mathbf{m L}$ & Interpretation $^{*}$ \\
\hline Amoxicillin-clavulanate & 16 & $\mathrm{~N} / \mathrm{A}$ \\
Piperacillin-tazobactam & 128 & $\mathrm{R}$ \\
Ceftriaxone & 8 & $\mathrm{~S}$ \\
Ceftazidime & 32 & $\mathrm{R}$ \\
Meropenem & 2 & $\mathrm{~S}$ \\
Ciprofloxacin & 16 & $\mathrm{R}$ \\
Levofloxacin & 4 & $\mathrm{I}$ \\
Colistin & 16 & $\mathrm{R}$ \\
Gentamicin & 0.5 & $\mathrm{~S}$ \\
Amikacin & 1 & $\mathrm{~S}$ \\
Trimethoprim-sulfamethoxazole & 0.12 & $\mathrm{~S}$ \\
Clindamycin & 8 & $\mathrm{~N} / \mathrm{A}$ \\
\hline
\end{tabular}

${ }^{*}$ Clinical and Laboratory Standards Institute (CLSI) minimum inhibitory concentration (MIC) interpretive standards for non-Enterobacteriaceae Gramnegative rods were applied: S Susceptible; I Intermediate; R Resistant; N/A No CLSI interpretive criteria exist

to bacteria in the genus Brevundimonas (10).

To date, Caulobacter species have rarely been documented to cause human infection. A review of the English language literature revealed only two reports describing the isolation of Caulobacter species from clinical specimens (7,11). Justesen et al (7) described a 64-year-old man who developed peritonitis while undergoing intermittent peritoneal dialysis for chronic renal insufficiency. Growth from the peritoneal fluid was observed in two aerobic blood culture bottles after four days of incubation. Using an API ID 32 GN strip (BioMérieux) and a VITEK 2 GN card, this isolate was identified as B vesicularis and $S$ paucimobilis, respectively. Interestingly, these are the same identities we obtained using commercial phenotypic identification systems. Sequencing of the $16 \mathrm{~S}$ ribosomal DNA gene was subsequently performed, and the isolate was determined to be Caulobacter species (7). The patient received intraperitoneal gentamicin and vancomycin. He subsequently died of other causes. The second report was published by Drancourt et al (11). These investigators used $16 \mathrm{~S}$ ribosomal DNA sequencing to identify $177 \mathrm{bac}$ terial isolates that could not be classified by conventional phenotypic methods. One of the isolates included in this study was identified as Caulobacter intermedius. This isolate was apparently obtained from a 'clinical source' (11). Unfortunately, no further details are provided regarding whether the isolate was of clinical significance.

Antimicrobial susceptibility of Caulobacter species has not been well described in the literature. There are no CLSI guidelines instructing how to perform testing for this genus, nor are interpretive criteria available. Justesen et al (7) performed susceptibility testing on their isolate using E-test strips, with the isolate inoculated onto Danish blood agar. These investigators applied CLSI breakpoints for nonfermentative Gram-negative rods. Based on these breakpoints, their isolate was susceptible to meropenem, imipenem, gentamicin, streptomycin, netilmicin, tobramycin, linezolid, rifampin, tetracycline and sulfadiazine. In general, this is similar to the susceptibilities reported in the present article.

There are several limitations to the current report that warrant attention. The first is that the Caulobacter species isolate recovered only grew in a blood culture bottle inoculated with CSF, and not on the agar plates that were directly inoculated with the clinical specimen. On this basis, the question could be raised as to whether the isolate may in fact represent an environmental contaminant introduced at the time of specimen inoculation/plating. While this cannot be entirely excluded, no other bacterial pathogen was isolated on culture despite collection of the CSF specimen before antimicrobial administration. The second limitation is that bacterial identification was made entirely on the basis of $16 \mathrm{~S}$ ribosomal DNA sequencing. We did not pursue further investigations to visualize the characteristic 
Caulobacter stalk. However, the sequencing was a very good match for Caulobacter species DNA and the limited biochemical investisgations performed here were in agreement with testing described by Justesen et al (7). Finally, the patient was discharged before the final organism was identified; the source of the organism in his CSF remains unclear. Because Caulobacter species have been recovered from tap water, it is quite possible that the isolate originated from a water source in the hospital environment. Environmental testing was not performed to confirm or refute this hypothesis. It is likely that the patient's recent neurosurgical manipulations also played a role in the pathogenesis.

\section{SUMMARY}

The present article describes a case of meningitis postneurosurgery, likely due to Caulobacter species, in a pediatric patient. The isolate in question was identified by commercial phenotypic identification systems as B vesicularis and S paucimobilis. However, both of these identities were inconsistent with the organism's Gram stain and colony morphology. The present case underscores the importance of reconciling conflicting phenotypic test results with the use of $16 \mathrm{~S}$ ribosomal DNA sequencing. Correct organism identification, in turn, is critical in defining the range of clinical manifestations and virulence potential of a given genus/species. In comparison with community-acquired bacterial meningitis, meningitis following neurosurgery is more likely to be caused by Gram-negative rods including Enterobacteriaceae and nonfermenters $(12,13)$. One should not discount the clinical significance of uncommon Gram-negative rods recovered from patient specimens in the appropriate clinical context.

\section{REFERENCES}

1. Poindexter JS. Biological properties and classification of the Caulobacter group. Bacteriol Rev 1964;28:231-95.

2. Henrici AT, Johnson DE. Studies of freshwater bacteria: II. Stalked bacteria, a new order of Schizomycetes. J Bacteriol 1935;30:61-93.
3. Abraham WR, Strompl C, Meyer H, et al. Phylogeny and polyphasic taxonomy of Caulobacter species. Proposal of Maricaulis gen. nov. with Maricaulis maris (Poindexter) comb. nov. as the type species, and emended description of the genera Brevundimonas and Caulobacter. Int J Syst Bacteriol 1999;49:1053-73.

4. Clinical and Laboratory Standards Institute. Methods for dilutional antimicrobial susceptibility tests for bacteria that grow aerobically. Approved standard, 7th edn. Wayne, 2006.

5. Clinical and Laboratory Standards Institute. Performance standards for antimicrobial susceptibility testing. Wayne, 2009.

6. Poindexter JS. Genus I. Caulobacter. In: Holt JG, Krieg NR, Sneath PH, Staley JT, Williams ST, eds. Bergey's Manual of Determinative Bacteriology, 10th edn. Baltimore: Williams \& Wilkins Co, 2005:287-303.

7. Justesen US, Holt HM, Thiesson HC, et al. Report of the first human case of Caulobacter sp. infection. J Clin Microbiol 2007;45:1366-9.

8. Bowers LE, Weaver RH, Grula EA, Edwards OF. Studies on a strain of Caulobacter from water. Isolation and identification as Caulobacter vibrioides Henrici and Johnson with emended description. J Bacteriol 1954;68:194-200.

9. Nierman WC, Feldblyum TV, Laub MT, et al. Complete genome sequence of Caulobacter crescentus. Proc Natl Acad Sci USA 2001;98:4136-41.

10. Sly LI, Cox TL, Beckenham TB. The phylogenetic relationships of Caulobacter, Asticcacaulis and Brevundimonas species and their taxonomic implications. Int J Syst Bacteriol 1999;49:483-8.

11. Drancourt M, Bollet C, Carlioz A, Martelin R, Gayral JP, Raoult D. $16 \mathrm{~S}$ ribosomal DNA sequence analysis of a large collection of environmental and clinical unidentifiable bacterial isolates. J Clin Microbiol 2000;38:3623-30.

12. Streharova A, Benca J, Holeckova K, et al. Comparison of postsurgical and community acquired bacterial meningitis - analysis of 372 cases within a nationwide survey. Neuro Endocrinol Lett 2007;28(Suppl 3):7-9.

13. van de Beek D, Drake JM, Tunkel AR. Nosocomial bacterial meningitis. N Engl J Med 2010;362:146-54. 


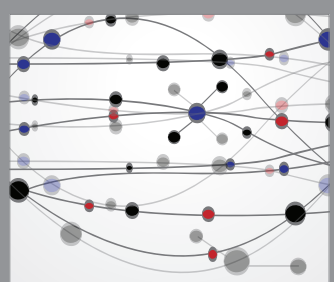

The Scientific World Journal
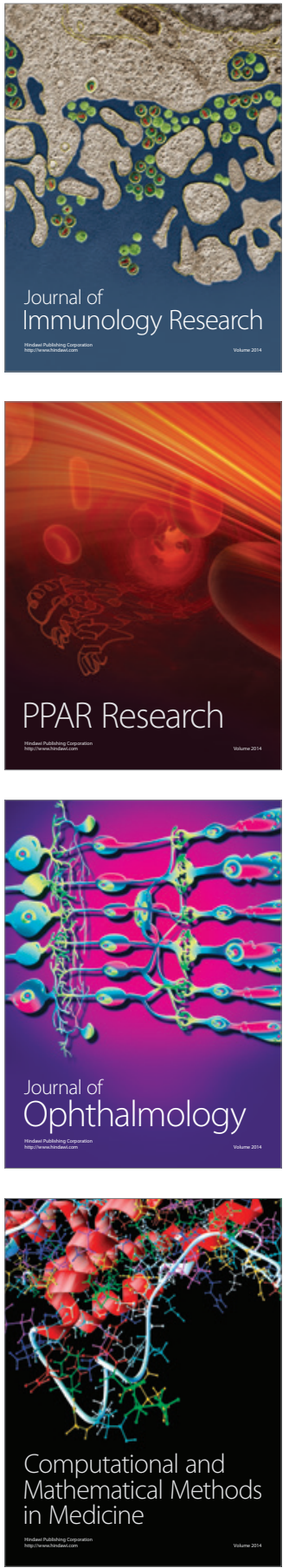

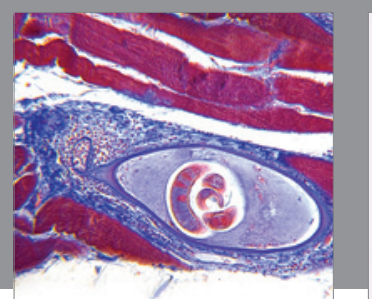

Gastroenterology Research and Practice

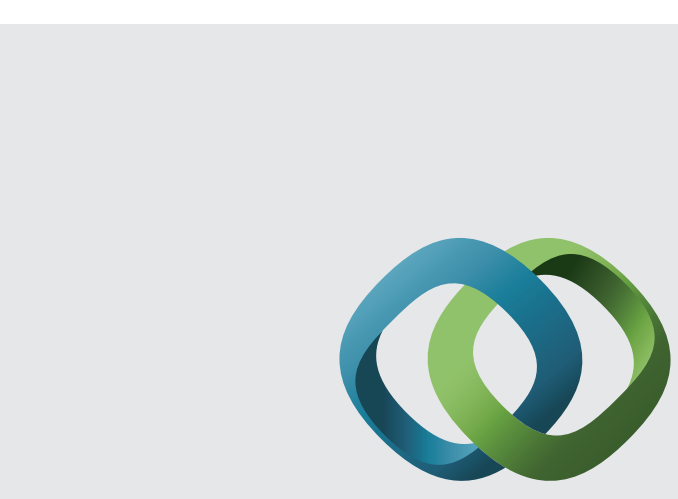

\section{Hindawi}

Submit your manuscripts at

http://www.hindawi.com
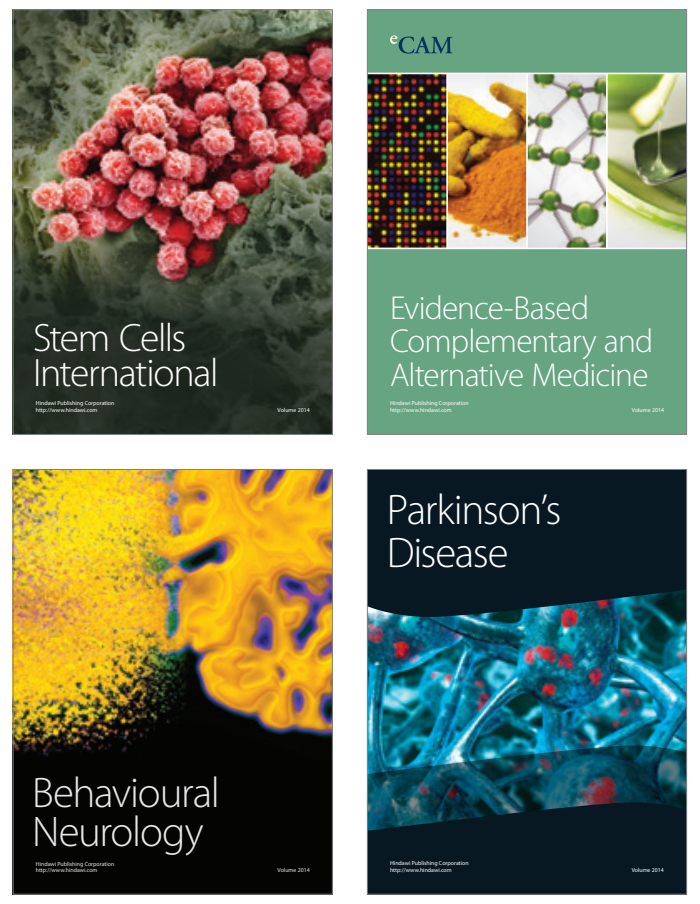
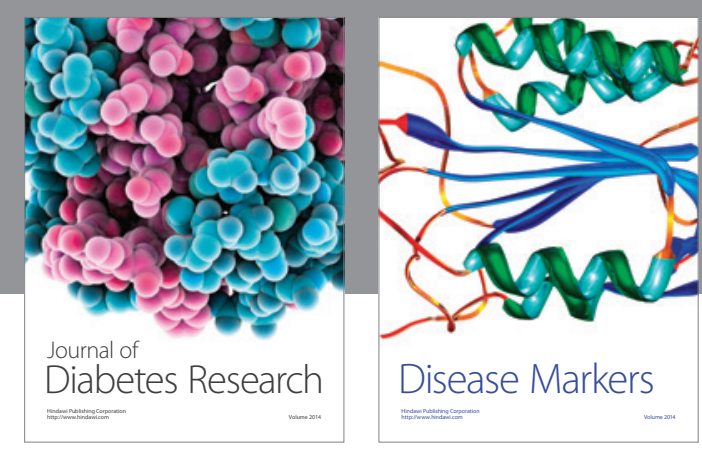

Disease Markers
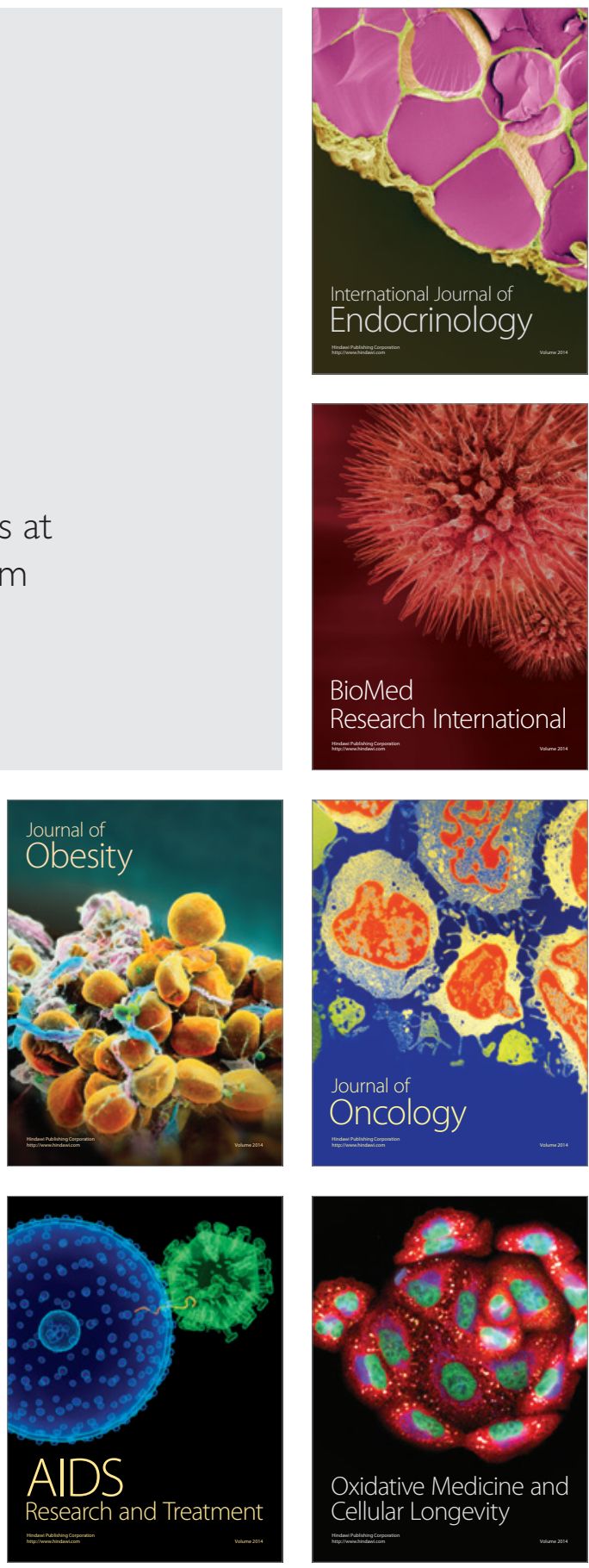